\title{
"Thinking Creatively with Sounds and Words: Sounds and Images IIA" validity study in the Turkish language
}

\author{
Asli Kaya ${ }^{1}$ \\ Sermin Bilen ${ }^{2}$
}

\begin{abstract}
Creativity, although it had existed since the existence of humanity, nowadays it is gaining more and more importance. In this process, creativity have been addressed in a variety of ways such as the studies of development on creativity and determination of the level of creativity. For this reason some scales or tests have been developed. Developed tests in a certain culture or language have reflect this culture and language's understanding and qualifications. It is important to be done in a systematic way to test or scale adaptation studies in order to be applicable and meaningful in different culture or language.

The purpose of this research is to study the validity of the Turkish language of the Test of Thinking Creatively with Sounds and Words: Sounds and Images IIA developed by Torrance and Cunnington.

Language validity study was conducted in the academic year 2014-2015 by Dokuz Eylül University Buca Education Faculty Department of Foreign Language Education and Literature Faculty Department of Translation and Interpreting 4. Grade students ( $\mathrm{n}=55)$. For the reliability and validity study, the Sounds and Images IIA Turkish form was conducted in the academic year 2014-2015 by Dokuz Eylül University, Adnan Menderes University, Muğla S1tk1 Koçman University Education Faculty Department of music Education 1.- 4. Grade students ( $n=276$ ).

The reliability of the test was determined through the value of Cronbach's Alpha. The Cronbach's Alpha value of the Sounds and Images IIA English form was determined .64, for the Sounds and Images IIA Turkish form was determined .61 [.60 $\leq \alpha<.90]$. To determine the correlation between English and Turkish forms the correlation analysis was made. The correlation was determined .81 and there is a positive significant relationship between scores $[\mathrm{r}=.81, \mathrm{p}<.01]$. There isn't statistically significant difference between the English and Turkish form scores $[\mathrm{t}=.29$, $\mathrm{p}>$.01].

The Sounds and Images IIA Turkish Form Cronbach's Alpha reliability coefficient is .61, Spearman-Brown split-half reliability coefficient is .59 [.60 $\leq \alpha<.90]$. This result shows that the Sounds and Images IIA Turkish Form is a reliable measuring instrument for Turkish language.
\end{abstract}

Keywords: Creativity; evaluation of creativity; thinking creatively with sounds and words; the Sounds and Images IIA; scale adaptation.

\footnotetext{
${ }^{1}$ Res. Asst., Dokuz Eylul University, Buca Faculty of Education, Department of Music Education, asli.kaya@,deu.edu.tr 2 Asst. Prof. Dr., Dokuz Eylul University, Buca Faculty of Education, Department of Music Education, sermin.bilen@,deu.edu.tr
} 
Kaya, A., \& Bilen, S.. (2017). "Thinking Creatively with Sounds and Words: Sounds and Images IIA" validity study in the Turkish language. Journal of Human Sciences, 14(4), 3956-3967. doi:10.14687/jhs.v14i4.5061

\section{Introduction}

Creativity is not a privilege of a few elite people, but it is a very important act that every person in need can refer to, that is necessary in inter-personal lives, in relationships, in many events or situations (Yavuzer, 1989: 9). San (2002) defines creativity as an ability that exists at all levels and can manifest itself in every part of human life, a set of processes that lead to the emergence of masterpieces from everyday life to scientific works or art, and also as a form of attitude or behavior (Cited in Üstündağ, 2011: 5).

According to Lowenfeld (1959), creativity is a kind of characteristic that individuals have in varying amounts and which is likely to emerge more or less depending on the situation (cited in Rouquette, 1982/1992: 14). Creativity, therefore, is a potential power that can be found in every person and can manifest itself in the presence of appropriate conditions.

Sungur (cited in 1992: 19,20) notes that systematic research on creative thinking began in the 1960s, and that the literature on creativity has developed in three different directions. First of these intends to describe the creative individual; and includes Guilford's (1967) studies in the cognitive domain, Mac Kinnon's (1962) studies on personality and Dunnette (1976), Gough (1976), and Torrance's (1972) studies on comprehension. The second set of research aims to find out which factors increase or inhibit creativity, while the other approach consists of studies aimed at training more creative individuals led by the studies of Osborn (1963), Parnes (1969), Gordon (1956) and Prince (1970).

Gordon states that the creative process can be fully analyzed, and no matter what the research topic is (technical, scientific, aesthetic), the creative process always activates same mechanisms and that the creation processes show similarities between individuals and groups (Rouquette, 1982/1992: 68).

While Maslow (1959) deals with creativity in two dimensions, as spontaneous, gushing and playful core creativity and controlled, disciplined and non-playful secondary creativity, Taylor (1959) presents five ranked levels of creativity. These are; expressive, productive, inventive, innovative, and emergent creativity. Expressive creativity exists originally in the individual; the demonstration of the individual is important and not the quality of the product. Productive creativity requires the activation of developed and controlled skills or predispositions. Even if the product is not original compared to what others have done, the individuals reach a higher behavioral stage. Inventive creativity is characterized by the perception of new relationships and involves the original use of previously gained experiences. Innovative creativity requires a high abstraction capacity and is a productive transformation of progression. Emergent creativity contains completely new basic principles (Rouquette, 1982/1992: 14, 15).

While Wallas (1926) addresses the process of creativity in four stages as "preparation, incubation, inspiration, and validation", Harris (1959) has argued that it consists of five consecutive stages, "the recognition of need, the gathering of knowledge, the thinking activity that processes this knowledge, the designing of solutions, validation and application". According to Harris, "the designing of solutions" is at the core of the creative process, whereas Wallas argues that it is "inspiration". According to Mednick (1962), there are three basic forms or ways of achieving a creative solution: "coincidence, similarity, and mediation" (Rouquette, 1982/1992: 18, 21).

Many researchers have developed scales and tests to determine the characteristics of creativity. Guilford notes that creativity and the characteristics specific to creative individuals should be examined, and describes the competence qualities that characterize creativity as the ability to see problems, smooth thought flow, thought flexibility, originality, redefining and processing. In order to measure the properties of originality, several ways has been suggested including the counting of answers that reflect intelligence, the use of ideas based on distant associations, and the evaluation of rare answers in all the answers of individuals within the society (Yavuzer, 1989: 15).

Lowenfeld et al. (1962), who determined the criteria of creativity, express that creative features in art consist of flexibility, fluency, originality, sensitivity to problems, redefinition and regulation, analysis, synthesis and organizational consistency (Cited by: Yavuzer, 1989: 35). 
Kaya, A., \& Bilen, S.. (2017). "Thinking Creatively with Sounds and Words: Sounds and Images IIA" validity study in the Turkish language. Journal of Human Sciences, 14(4), 3956-3967. doi:10.14687/jhs.v14i4.5061

Many studies have been carried out by Getzels and Kogan (1965), Torrance (1962), Wallach and Kogan (1965) to reveal the relationship between intelligence and creativity. Torrance notes that if talented children are identified only by classical intelligence tests, about 70 percent of the most creative subjects are eliminated. The work of Wallach and Kogan also reveals that intelligence and creativity are two largely independent dimensions (Rouquette, 1982/1992: 16).

Mc. Kinnon (1962) also notes that there is no high level of relationship between creativity and intelligence, and that it is difficult to say that a more intelligent individual will be more creative (Cited by: Sungur, 1992: 77).

At the heart of many creativity tests is the idea that each individual has a varying amount of creativity. These tests attempt to take into account the potential of the individual to produce original answers with a set of appropriate evidences, either by creating simulations of various creative situations or by encouraging the application of a special intellectual function (Rouquette, 1982/1992: 14).

A number of creativity tests have been developed with the aim of determining the level of creativity, and creativity has been dealt with in different aspects. One of the tests developed is the Thinking Creatively with Sounds and Words test, developed by Cunnington and Torrance and Khatena.

Thinking Creatively with Sounds and Words test consists of two independent tests: "Sounds and Images" and "Onomatopoeic Words and Images" where the level of creativity is assessed by responses to auditory stimuli. Sounds and Images test was developed by Torrance and Cunnington, whereas Onomatopoeic Words and Images test was developed by Khatena. The aim of the test is to show how advanced an individual's creativity and imagination is. The main characteristic is that it evaluates creative thinking through auditory stimuli, unlike the formal and verbal form of the Torrance Creative Thinking test. The test is a useful and functional measurement tool that measures the original thinking potential of children, adolescents, and adults (Khatena and Torrance, 1998: I).

The Sounds and Images form consists of 4 different sounds that go from concrete sounds to abstract sounds and specifically designed to maximize your imagination. These four groups of sounds are played three times at intervals of 15 seconds, and each time a sound is heard, the participant is asked to imagine an original image related to that sound. The Onomatopoeic Words and Images form consists of 10 reflective words whose musical qualities are different from ordinary words. This group of words, which is read four times over a short period of time, is carefully listened to and individuals are asked to animate an original image related to each word. Each form has a separate scoring guide. The feedbacks given to the forms where scoring is done within the scope of the originality dimension of creativity are scored from 0 to 4 with the scoring guide in the manual. The highest score to be taken from the Sounds and Images form is 48 , while the highest score that can be obtained from the Onomatopoetic Words and Images form is 160 (Torrance, Khatena and Cunnington, 1990: 4-8).

This test has been prepared for two levels; where Level I is for Grades 3-12, whereas Level II is for adults. In addition, each level consists of two equal forms for the pre-test and post-test (form A and B) <http://ststesting.com/2005gifttcsw.html> (Last accessed: 17.11.2017).

The aim of this study is to conduct the Turkish language validity and reliability study of the Creative Thinking with Sounds and Images IIA form developed by Torrance and Cunnington as part of the Creative Thinking Test with Sounds and Images. Turkish language equivalence, reliability and validity studies have been carried out by obtaining the necessary permissions from Scholastic Testing Service, which has publishing rights for the adaptation of the form in Turkish. 
Kaya, A., \& Bilen, S.. (2017). "Thinking Creatively with Sounds and Words: Sounds and Images IIA" validity study in the Turkish language. Journal of Human Sciences, 14(4), 3956-3967. doi:10.14687/jhs.v14i4.5061

\section{Method}

Tests that are developed in a particular culture and language reflect a certain set of understanding and qualities specific to that culture and language. It is important to perform scale adaptation studies systematically so that the same test can be applied and be meaningful in different cultures and languages. Öner $(2012: 21,22)$ states what should be done in scale adaptation study, which he defines as adaptation model, as follows:

In the first stage of the model, the test items are translated and the language equivalence of the test is tested by empirical methods to examine the psycholinguistic qualities. Original test items and items of the translated form are then applied to groups consisting of individuals who are bilingual or fluent in both languages (sample), and the responses are compared. If the translation is done well, and the items are clear and comprehensible, they constitute meaningful expressions for the participants. In this case, there are no statistically significant differences between the responses given to the original and the translated items. Thus the language differences hypothesis has been tested and rejected.

In the second stage, the psychometric properties of the translation form -for which language equivalency is determined- are examined. Here, the reliability and validity of the translation test items are tested. Invariance, homogeneity and internal consistency tests can be performed for reliability; whereas criterion-dependent (both time, procedure), structure (theory-concept, hypothesis) etc. validity techniques can be applied for validity.

In the third stage, the culture-dependent qualities of the adapted test are examined. The new (translated) language norms and the original language norms (if adapted to other languages, their norms as well) are compared. In addition, questions such as "Does the factor structure, and the factor load of the new test resemble the original form?", "If there are differences, can they be explained with characteristics like language, culture, etc.?" are answered.

Therefore, in this study, the scale adaptation steps that proposed by Öner were applied.

\section{Study group}

Pilot application of the translation within the context of language validity study was conducted with 4th grade students $(n=55)$ who were studying in Dokuz Eylül University Buca Education Faculty Department of Foreign Language Education and Literature Faculty Department of Translation and Interpreting in 2014-2015 academic year. Two weeks after the English test was applied, the Turkish translation was applied on the same students. In the first application, students were asked to write their images about the voices they heard in English, whereas in the second application, they were asked to write their images in Turkish.

The reliability and validity study of the Thinking Creatively with Sounds and Words "Sounds and Images IIA" form, for which Turkish linguistic equivalency was established, was performed on data collected from 107 students from Dokuz Eylül University, Buca Faculty of Education, Fine Arts Education and Department of Music Education, 86 students from Adnan Menderes University, Faculty of Education, Department of Fine Arts, Department of Music Education, and 83 students from Muğla Sitkı Koçman University Faculty of Education Fine Arts Education Department Music Education Department, with a total of 276 students from grades 1-4 continuing their education in the 2014-2015 academic year. 
Kaya, A., \& Bilen, S.. (2017). "Thinking Creatively with Sounds and Words: Sounds and Images IIA" validity study in the Turkish language. Journal of Human Sciences, 14(4), 3956-3967. doi:10.14687/jhs.v14i4.5061

\section{Results}

\subsection{Linguistic equivalence results}

Within the scope of linguistic equivalence studies, the Thinking Creatively with Sounds and Words "Sounds and Images IIA" form and the scoring manual were translated into Turkish by three experts, and a joint form and scoring manual was developed from the three translations. Subsequently, the joint form and scoring manual was translated back into the original language and their consistency with the original structures was examined. In this examination, it was seen that there was language equivalence between the original form and the scoring manual and the translations made from Turkish, and structural equality was established by making necessary corrections in the Turkish form and scoring manual. In adapted tests, the primary concern is structural equality. Structural equality is determined by experts who are familiar with both cultures and the measurement topic (Şencan, 2005: 607, 609).

English and Turkish forms were applied on 33 female and 22 male $(\mathrm{n}=55)$ students continuing their education in Dokuz Eylül University, Buca Education Faculty, Foreign Languages Education Department English Language Education Department, and Literature Faculty Translation and Interpretation Department during 2014-2015 academic year.

The data obtained from Creative Thinking with Sounds and Words "Sounds and Images IIA" English and Turkish forms were subjected to Kolmogorov-Smirnov normality test to assess the distribution of the data. Normality test results are shown in Table 1.

Table 1. Sounds and Images IIA Form normality test results

\begin{tabular}{cccc}
\hline & Kolmogorov-Smirnov & sd & p \\
\hline English Form & .097 & 55 & $.20^{*}$ \\
\hline Turkish Form & .113 & 55 & .08 \\
\hline Difference between averages & .096 & 55 & $.20^{*}$ \\
\hline $\mathrm{p}>0.05$ & & &
\end{tabular}

The Kolmogorov-Smirnov normality test, based on testing whether the data fit a normal probability distribution of a defined universe, tests the hypothesis that "there is no difference between the distribution of the available data and the normal probability distribution", and a " $\mathrm{p}$ value" greater than 0.05 means the data is normally distributed (Can, 2013: 88,89). The p value obtained in the normality test on the data is greater than 0.05 , as seen in Table 1 . According to this result, the data of the Sounds and Images IIA English and Turkish Forms and the difference between the averages of the forms show a normal distribution [ $p>0.05]$.

Cronbach's alpha coefficients were calculated to test the reliability of the data obtained from the Thinking Creatively with Sounds and Words "Sounds and Images IIA" in English and Turkish forms. Cronbach's alpha reliability coefficients for the forms are given in Table 2.

Table 2. Reliability coefficients of English and Turkish forms

\begin{tabular}{ccc}
\hline & $\boldsymbol{\alpha}$ & Number of Items \\
\hline English Form & .64 & 4 \\
\hline Turkish Form & .61 & 4 \\
\hline Overall & .81 & 8 \\
\hline
\end{tabular}

According to the data in Table 2, reliability coefficient of the English form is .64, and reliability coefficient of the Turkish form is .61 . These results indicate that the measurements are highly reliable $[.60 \leq \alpha<.90]$. Reliability in measurements are expressed with the reliability coefficients. The coefficient usually takes a value between 0 and +1 , and the closer it is to 1 , the greater the reliability (Can, 2013: 340). 
Kaya, A., \& Bilen, Ş. (2017). "Thinking Creatively with Sounds and Words: Sounds and Images IIA" validity study in the Turkish language. Journal of Human Sciences, 14(4), 3956-3967. doi:10.14687/jhs.v14i4.5061

In order to determine the significance between the feedback given to Creative Thinking with Sounds and Words "Sounds and Images IIA" in English and Turkish forms and the sounds in the forms, and form scores in general, Pearson Moment Product Correlation (Simple Linear Correlation) analysis was performed. Simple Linear Correlation is used to describe the linear relationship between two variables measured on a range or ratio scale. Correlation coefficient $(r)$ is between -1 and +1 , and the closer the value is to 1 , the higher the correlation between the variables (Büyüköztürk, Çokluk and Köklü, 2013: 91, 92).

The correlations results between Sounds and Images IIA English and Turkish forms are shown in Table 3.

Table 3. English and Turkish Forms correlation results

\begin{tabular}{|c|c|c|c|}
\hline & $\mathbf{N}$ & $\mathbf{r}$ & $\mathrm{p}$ \\
\hline Sound 1 & 55 & $.59^{* *}$ & .00 \\
\hline Sound 2 & 55 & $.69^{* *}$ & .00 \\
\hline Sound 3 & 55 & $.47^{* *}$ & .00 \\
\hline Sound 4 & 55 & $.50^{* *}$ & .00 \\
\hline Overall & 55 & $.81^{* *}$ & .00 \\
\hline
\end{tabular}

Correlation coefficient between English and Turkish scores was found to be .81 . Correlations on individual sounds were found to be .59 for Sound 1, .69 for Sound 2, .47 for Sound 3 , and .50 for Sound 4. Positive and significant correlations were found between the scores of English and Turkish forms $[\mathrm{p}<0.01]$.

t-test was conducted to determine the significance of the difference between English and Turkish scores. For related samples, the t-test (Paired Sample t-test) is used to determine whether there is a statistically significant difference between the averages of the data obtained from two successive measurements on the same data source (Can, 2013: 132). The results of the paired sample t-test are shown in Table 4.

Table 4. Paired t test results for English and Turkish forms

\begin{tabular}{cccccccc} 
& $\mathbf{n}$ & $\overline{\boldsymbol{X}}$ & $\mathbf{S}$ & $\begin{array}{c}\text { Difference } \\
\text { between } \\
\text { averages }\end{array}$ & $\mathbf{s d}$ & $\mathbf{t}$ & $\mathbf{p}$ \\
\hline English Form & 55 & 21.85 & 8.63 & .29 & 54 & .40 & .68 \\
\hline Turkish Form & 55 & 21.56 & 8.58 & & & &
\end{tabular}

The difference between English and Turkish scores is .29. The p-value of the paired sample t-test was found to be .68. Therefore, there was no statistically significant difference between the English and Turkish scores, and the gap hypothesis stated as "There is no difference between the score averages of Sounds and Images IIA English and Turkish Forms" was accepted [p $>0.01]$.

In order to assess rater reliability, Creative Thinking with Sounds and Words "Sounds and Images IIA" English and Turkish forms of 10 randomly picked students were evaluated by an external expert, and inter-rater reliability was assessed by Kendall's W coefficient (Kendall's Coefficient of Concordance).

Kendall's coefficient of concordance is a non-parametric test that assesses whether there is a significant level of concordance between the evaluations of multiple raters on a group. Kendall's Coefficient of Concordance takes a value between 0 and 1 , and a value closer to 1 implies a high level of concordance (Can, 2013: 348). 
Kaya, A., \& Bilen, S.. (2017). "Thinking Creatively with Sounds and Words: Sounds and Images IIA" validity study in the Turkish language. Journal of Human Sciences, 14(4), 3956-3967. doi:10.14687/jhs.v14i4.5061

Kendall's W Coefficient of Concordance Results for Sounds and Images IIA English and Turkish forms are presented in Table 5.

Table 5. Kendall's W concordance coefficient results

\begin{tabular}{cccccc}
\hline & $\mathbf{n}$ & $\mathbf{W}$ & $\mathbf{x}^{2}$ & $\mathbf{s d}$ & $\mathbf{p}$ \\
\hline English Form & 2 & .98 & 17.61 & 9 & .04 \\
\hline Turkish Form & 2 & .96 & 17.28 & 9 & .04 \\
\hline $\mathrm{p}<0.05$ & & & &
\end{tabular}

There is statistically significant concordance between the evaluations made by the two evaluators for the English Form [W:.98, p<.05]. There is also a statistically significant concordance among the evaluations for the Turkish Form [W:.96, p<.05].

Discriminant (function) analysis was conducted to investigate the difference between the groups that filled out the Thinking Creatively with Sounds and Words "Sounds and Images IIA" English and Turkish Forms (Dokuz Eylül University, English Language Education Department and Translation and Interpreting Department).

Discriminant analysis is a multivariate statistical technique that serves to establish a predictive model of group members. Factor analysis is the most common way of examining the similarities between variables in behavioral sciences. Although their purposes are not the same, the three most popular methods for examining the similarities between variables are clustering analysis, profile analysis, and discriminant analysis. Discriminant analysis can be performed to investigate differences between groups (Çokluk et al., 2012: 105, 106, 107).

The Wilks' lambda test results for equality of group averages performed for the discriminant analysis are given in Table 6.

Table 6. Group average equalities test results

\begin{tabular}{|c|c|c|c|c|c|}
\hline & & $\mathbf{F}$ & sd1 & $\mathrm{sd} 2$ & $p$ \\
\hline English Form & .93 & 3.79 & 1 & 53 & .06 \\
\hline Turkish Form & .95 & 2.78 & 1 & 53 & .10 \\
\hline
\end{tabular}

Wilks' Lambda $(\lambda)$ takes a value between 0 and 1.0 means that the group means are different, and 1 means that the group means are similar or not different (Diekhoff, 1992; Garson, 2008; Cited by: Çokluk et al., 2012: 12).

According to the Wilks' Lambda data in Table 6, the group averages for the English and Turkish forms of students of the English Language Education Department and the Translation and Interpretation Department are similar $\left[\lambda_{\text {EnglishForm }}=.93, \mathrm{p}>.05\right.$ and $\left.\lambda_{\text {TurkishForm }}=.95, \mathrm{p}>.05\right]$.

In conclusion, based on the results obtained by Cronbach Alfa Reliability analyses, analyses of correlation and difference between forms, concordance analysis between evaluators, and difference analyses between the groups indicate that Turkish version of the Thinking Creatively with Sounds and Words "Sounds and Images IIA" form is a valid measurement tool.

\subsection{Reliability and validity results}

The reliability and validity study of the Thinking Creatively with Sounds and Words "Sounds and Images IIA Turkish" form was conducted with data obtained from a total of 276 students (157 female and 119 male) attending Music Education Departments of Dokuz Eylul University, Adnan Menderes University and Muğla Sitkı Koçman University.

Central tendency and Kolmogorov-Smirnov normality test results of the Thinking Creatively with Sounds and Words "Sounds and Images IIA Turkish" form are given in Table 7. 
Kaya, A., \& Bilen, Ş. (2017). "Thinking Creatively with Sounds and Words: Sounds and Images IIA" validity study in the Turkish language. Journal of Human Sciences, 14(4), 3956-3967. doi:10.14687/jhs.v14i4.5061

Table 7. Sounds and Images IIA Turkish form central tendency and normality test results

\begin{tabular}{cc}
\hline $\mathbf{n}$ & 276 \\
\hline Mean & 20.36 \\
\hline Median & 20.00 \\
\hline Peak Value & 20.00 \\
\hline Skewness & .18 \\
\hline Ktandard Error of Skewness & .15 \\
\hline Kurtosis & -.44 \\
\hline Standard Error of Kurtosis & .30 \\
\hline Kolmogorov-Smirnov & .05 \\
\hline $\mathbf{p}$ & .20 \\
\hline
\end{tabular}

When the central tendency and Kolmogorov-Smirnov normality test results are examined, it is seen that the Sounds and Images IIA Turkish Form data have an ideal normal distribution [p > $0.05]$.

The Kolmogorov-Smirnov normality test is based on testing whether the data fit a normal probability distribution of a defined universe. A " $p$ value" greater than 0.05 means the data is normally distributed. In an ideal normal distribution, mean, median and peak value overlap; the closer these three values are to each other, the more normal distribution characteristics the data will exhibit (Can, 2013: 82, 88, 89).

In order to determine the reliability of the measurements made for the Thinking Creatively with Sounds and Words "Sounds and Images IIA Turkish" form, Cronbach Alfa and SpearmanBrown Split-Half reliability coefficient analyses were performed.

In the reliability tests conducted with split test scores, the items in the measurement tool are generally divided into two equal groups as single and odd numbered items, and the relationship between the groups is calculated (Karasar, 2006: 150). Therefore, split-half method divides the form into two equal pieces, allowing for the estimation of reliability by correlating the scores of participants obtained from both halves.

As a result of the reliability analysis, the Cronbach Alpha coefficient for the Turkish version of Sounds and Images IIA was found to be .61. This result indicates that the measurement is quite reliable $[.60 \leq \alpha<.90]$. The Spearman-Brown reliability coefficient was found to be .59 . This result indicates that the measurement is reliable at an acceptable level.

The correlation results between the sounds taken from the Sounds and Images IIA Turkish Form and the scores obtained from the overall form are given in Table 8.

Table 8. Sounds and Images IIA Turkish form correlation results

\begin{tabular}{ccccc}
\hline & Sound 1 & Sound 2 & Sound 3 & Sound 4 \\
\hline \multirow{2}{*}{ Sound 2 } & $\mathrm{r}=.35^{* *}$ & & & \\
& $\mathrm{p}=.00$ & & & \\
\hline \multirow{2}{*}{ Sound 3 } & $\mathrm{r}=.20^{* *}$ & $\mathrm{r}=.31^{* *}$ & & \\
& $\mathrm{p}=.00$ & $\mathrm{p}=.00$ & & \\
\hline \multirow{2}{*}{ Sound 4 } & $\mathrm{r}=.31^{* *}$ & $\mathrm{r}=.28^{* *}$ & $\mathrm{r}=.25^{* *}$ & \\
& $\mathrm{p}=.00$ & $\mathrm{p}=.00$ & $\mathrm{p}=.00$ & \\
\hline \multirow{2}{*}{ Overall } & $\mathrm{r}=.67^{* *}$ & $\mathrm{r}=.72^{* *}$ & $\mathrm{r}=.66^{* *}$ & $\mathrm{r}=.67^{* *}$ \\
& $\mathrm{p}=.00$ & $\mathrm{p}=.00$ & $\mathrm{p}=.00$ & $\mathrm{p}=.00$ \\
\hline $\mathrm{p}<0.01$ & & & &
\end{tabular}


Kaya, A., \& Bilen, S.. (2017). "Thinking Creatively with Sounds and Words: Sounds and Images IIA" validity study in the Turkish language. Journal of Human Sciences, 14(4), 3956-3967. doi:10.14687/jhs.v14i4.5061

The correlation between the overall score obtained from the form and Sound 1 was found to be .67 , Sound 2 was found to be .72, Sound 3 was found to be .66, and Sound 4 was found to be .67. These correlations are positive and significant $[\mathrm{p}<0.01]$.

Discriminant (function) analysis was performed to investigate the differences between the groups according to the class levels of the students who completed the Thinking Creatively with Sounds and Words "Sounds and Images IIA" form. Table 9 shows the Wilks' Lambda group averages' equality test results for the sounds in the form and the overall scores.

Table 9. Group average equalities test results

\begin{tabular}{cccccc}
\hline & $\boldsymbol{\lambda}$ & $\mathbf{F}$ & $\mathbf{s d 1}$ & $\mathbf{s d 2}$ & $\mathbf{p}$ \\
\hline Sound 1 & .99 & .70 & 3 & 272 & .55 \\
\hline Sound 2 & .99 & 1.21 & 3 & 272 & .31 \\
\hline Sound 3 & .99 & .39 & 3 & 272 & .76 \\
\hline Sound 4 & .98 & 1.47 & 3 & 272 & .23 \\
\hline Overall & .99 & 1.10 & 3 & 272 & .34 \\
\hline $\mathrm{p}>0.05$ & & & & &
\end{tabular}

Since Wilks' Lambda takes a value between 0 and 1, based on the Wilks' Lambda values presented in Table 9, group averages of the students in terms of class level are similar to each other $\left[\lambda_{\text {Sound } 1}=.99, \lambda_{\text {Sound } 2}=.99, \lambda_{\text {Sound } 3}=.99, \lambda_{\text {Sound } 4}=.98, \lambda_{\text {Overall }}=.99, \mathrm{p}>.05\right]$.

Exploratory and confirmatory factor analysis was performed to evaluate the structural validity of the Sounds and Images IIA Turkish form. Exploratory factor analysis is a process that obtains the factors based on the relationship between the variables (Büyüköztürk, 2009: 123). The item factor loads obtained by the exploratory factor analysis, KMO values and Bartlett Test results are presented in Table 10.

Table 10. Sounds and Images IIA Turkish form item factor loads and KMO value and Bartlett Test results

\begin{tabular}{cc}
\hline Items & $\begin{array}{c}\text { Factor } \\
\text { (Sounds and Images IIA Turkish) }\end{array}$ \\
\hline Sound 1 & .69 \\
\hline Sound 2 & .73 \\
\hline Sound 3 & .62 \\
\hline Sound 4 & .67 \\
\hline $\mathrm{p}<0.05$ & $\mathrm{KMO}=.68 ;$ Bartlett Test $\mathrm{p}=.00 ;$ Total Explained Variance $=46.11$ \\
\hline
\end{tabular}

Based on the component matrix in Table 10, the factor loads of items in a single factor vary between .62 and .73 . Total variance that is explained by all factors is $46 \%$. KMO value indicates that the scale is suitable for exploratory factor analysis [.68 $>.50]$, and Bartlett Test results indicate that there is a high correlation between the variables $[\mathrm{p}<0.05]$. KMO value shows sample adequacy. Here, adequacy is in terms of the relationships, and not the number. Bartlett Test tests whether there is a significant difference between the actual correlation matrix with relationships among the items and the unit matrix (Can, 2013: 277).

In order to test the suitability of the factors determined by the exploratory factor analysis with the items, confirmatory factor analysis was performed for the single-factor model. Confirmatory factor analysis is a process for testing a previously determined hypothesis or theory about the relationship between variables (Büyüköztürk, 2009: 123), and with this analysis, coefficients for structural validity can be generated (Çokluk et al., 2012: 285). 
Kaya, A., \& Bilen, Ş. (2017). "Thinking Creatively with Sounds and Words: Sounds and Images IIA" validity study in the Turkish language. Journal of Human Sciences, 14(4), 3956-3967. doi:10.14687/jhs.v14i4.5061

The Critical N (CN) value, which assesses sample adequacy for the confirmatory factor analysis for the Sounds and Image IIA Turkish form, was calculated as 701.41. A Critical N value of 200 or more is considered to be an indicator of adequate model suitability (Yllmaz and Çelik, 2009: 116).

The significance levels of the rate of observed variables (Sounds 1-4) explaining the latent variable (Sounds and Images IIA) are presented with $\mathrm{t}$ values in Figure 1.

Figure 1. $\mathrm{t}$-value path diagram of the rate of observed variables explaining the latent variable

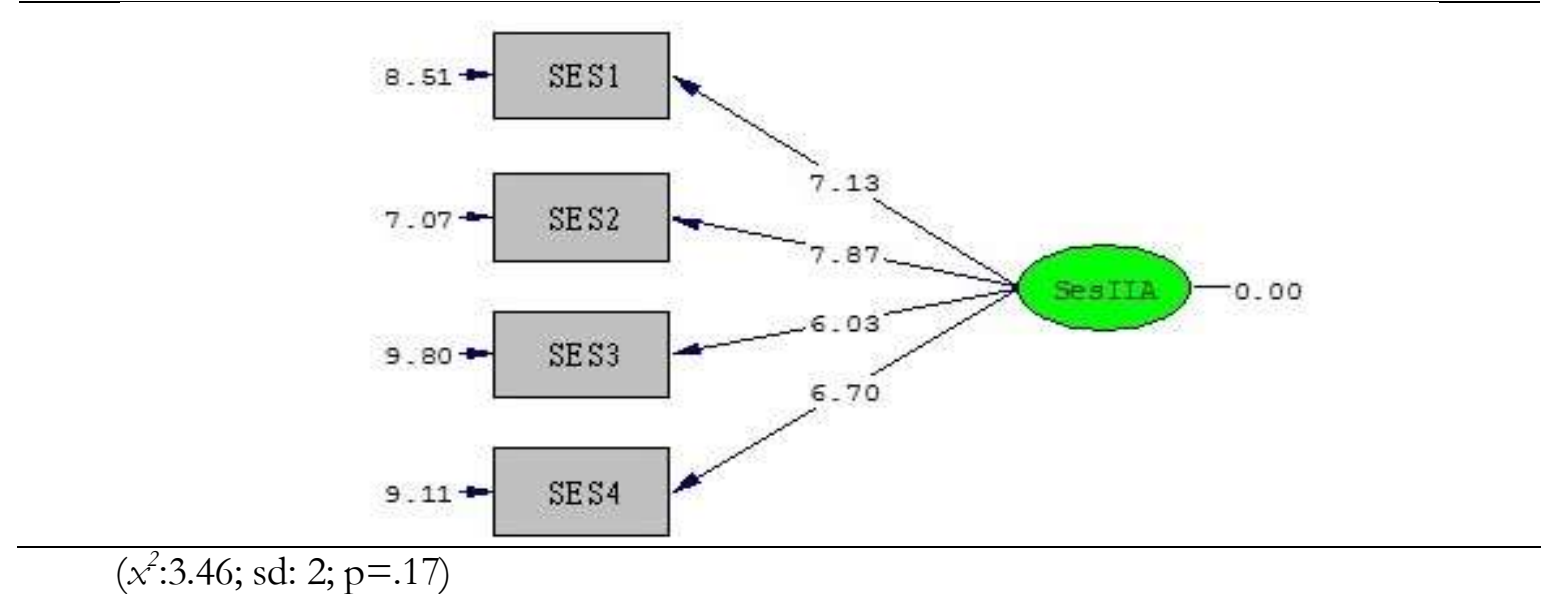

The researcher must first check the significance level of the $t$ values of the observed variables. The $t$ values of the observed variables explaining the latent variable are shown on the arrows. A t value exceeding 1.96 indicates a significance level of 0.05 , and a t value exceeding 2.56 indicates a significance level of 0.01 (Çokluk et al., 2012: 304). According to Figure 1, the rates of Sounds 1-4 explaining the Sounds and Images IIA form are significant at a level of 0.01 .

Concordance index values of the Sounds and Images IIA Turkish form are given in Table 11.

Table 11. Concordance index values of the Sounds and Images IIA Turkish form

\begin{tabular}{ccc}
\hline Concordance Measure & Value & Concordance \\
\hline$x^{2} /$ sd & 1.73 & Perfect \\
\hline RMSEA & .05 & Perfect \\
\hline NFI & .97 & Perfect \\
\hline NNFI & .96 & Perfect \\
\hline CFI & .99 & Perfect \\
\hline GFI & .99 & Perfect \\
\hline AGFI & .97 & Perfect \\
\hline
\end{tabular}

According to Table 11, the ratio of chi-square and degree of freedom, $x^{2} / \mathrm{sd}$ is 1.73 , whereas $\mathrm{p}=0.17$. In large samples, a $x^{2} /$ sd ratio smaller than 3 indicates perfect concordance, while a ratio smaller 5 indicates intermediate concordance (Kline, 2005; Sümer 2000; Cited by: Çokluk et al., 2012: 307). $\mathrm{p}$ value is 0.17 . The significance of the $\mathrm{p}$ value which indicates the significance of the difference between the expected covariance matrix and observed matrices ( $x^{2}$ value) may be neglected in many studies. For this reason, it is useful to evaluate alternative concordance indices to assess concordance between the two matrices (Çokluk et al., 2012: 307).

The values for other concordance indices as shown in Table 11 are; Root Mean Square Error of Approximation, RMSEA: .05; Normed Fit Index, NFI: .97; Non-Normed Fit Index, NNFI: .96; Comparative Fit Index, CFI: .99; Goodness of Fit Index, GFI: .99; and Adjusted 
Kaya, A., \& Bilen, S.. (2017). "Thinking Creatively with Sounds and Words: Sounds and Images IIA" validity study in the Turkish language. Journal of Human Sciences, 14(4), 3956-3967. doi:10.14687/jhs.v14i4.5061

Goodness of Fit Index, AGFI: .97. Çokluk et al. states that a RMSEA value lower than .05 indicates a perfect fit, and a value lower than .08 indicates a good fit; whereas NFI, NNFI, CFI, GFI and AGFI values higher than .95 indicate a perfect fit $(2012: 307,312)$. Based on the obtained values, it can be stated that the Sounds and Images IIA Turkish form has a perfect fit index in general.

\section{Conclusions and discussion}

Cronbach Alpha general reliability coefficient of the measurement related to the Sounds and Images IIA English form was found to be .64, whereas that of the Turkish form was .61 [.60 $\leq$ $\alpha<.90]$. According to Kolmogorov-Smirnov normality test result, the data of the English and Turkish forms were normally distributed [p $>0.05]$.

The correlation coefficient between the scores of the Sounds and Images IIA English and Turkish forms was found to be .81. There was a positive and significant relationship between English and Turkish scores $[\mathrm{r}=.81, \mathrm{p}<.01]$. In addition, there was no statistically significant difference between English and Turkish scores [ $t=.29, \mathrm{p}>.01]$.

In order to measure the reliability of the evaluators, the forms of 10 students randomly selected from the participating students were scored by another expert and the inter-rater reliability was assessed. There is statistically significant concordance between the two evaluators' evaluations of the Sounds and Images IIA English Form [W: .97, p <.05]. There is also a statistically significant level of concordance for Sounds and Images IIA Turkish Form [W: .96, p <.05].

The central tendency and Kolmogorov-Smirnov normality test values for the data obtained from the Sounds and Images IIA Turkish Form indicate that the data have an ideal normal distribution $[\mathrm{p}>0.05]$.

Cronbach Alpha coefficient for the Sounds and Images IIA Turkish form was found to be .61. This result indicates that the measurement is quite reliable $[.60 \leq \alpha<.90]$. The SpearmanBrown half-split reliability coefficient was .59. This result indicates that the measurement is reliable at an acceptable level.

In the study of Batıbay and Piji (2006: 59) conducted on 187 university students, the Cronbach's alpha reliability coefficient of the Thinking Creatively with Sounds and Words Test was calculated to be 66 .

Studies conducted on the reliability of the Thinking Creatively with Sounds and Words "Sounds and Images IIA" original form are as follows:

The Cronbach Alpha coefficient for the reliability study conducted by the answers of summer school students of the Texas Women's University $(n=201)$ was found to be .82 , and the Spearman-Brown Split-Half reliability coefficient was found to be .79. In the reliability study conducted on the students of the Mississippi State University $(n=183)$, Cronbach's alpha coefficient was .55, and Spearman-Brown Split-Half reliability coefficient was .47 (Khatena and Torrance, 1998: 14).

KMO and Bartlett Test results showed that the scale was suitable for exploratory factor analysis [.68> .50], and a high correlation existed between variables [ $\mathrm{p}<0.05]$. According to the components matrix, the factor loadings of the items took values between .62 and .73 , and were collected under one factor. According to the confirmatory factor analysis results, which is performed to test a pre-determined hypothesis or theory for a relationship between variables, the Turkish Form appears to have a perfect fit index in general [ $x^{2} / \mathrm{sd}: 1.73 ; \mathrm{p}=.17$; RMSEA: .05].

In the item discrimination analyses performed by Batıbay and Piji (2006: 59) in their study conducted on 187 university students, significant results at a level of 0.01 were obtained [ $p<.01]$.

The validity study of the original form was conducted by looking at the correlation of the Sounds and Images IIA with various scales (Khatena and Torrance, 1998: 24).

In a study conducted on 41 students graduated from Georgia University, a significant relationship was found between the Sounds and Images IIA form and Guglielmino's Self-Directed Learning Readiness Scale [r= .52; $\mathrm{p}<.01]$. 
Kaya, A., \& Bilen, S.. (2017). "Thinking Creatively with Sounds and Words: Sounds and Images IIA" validity study in the Turkish language. Journal of Human Sciences, 14(4), 3956-3967. doi:10.14687/jhs.v14i4.5061

In a study conducted on 38 students from Georgia University using the Musical Aptitude Profile of Gordon, a significant relationship was found between the Musical Sentence and Musical Style factors within the test and the Sounds and Images IIA form $[r=.32$ and $r=.31 ; p<.05]$. In addition, the musical compositions of each student were scored in terms of originality from 1 to 5 by the instructors, and a significant relationship was found between the scores obtained and the Sounds and Images IIA form $[\mathrm{r}=.34 ; \mathrm{p}<.05]$.

In a study on 188 students attending the summer seminars in Texas Women's University, a significant correlation of .20 was found between the Sounds and Images IIA and Kirton's Adaption-Innovation Inventory, a significant correlation of .28 and .21 was found with the Something About Myself? and What Kind of Person Are you? factors of Khatena and Torrance's Creative Perception Inventory, and a significant correlation of .40 was found with the Onomatopoeia and Images $[\mathrm{p}<.01]$.

In conclusion; based on the results obtained by Cronbach Alfa and Spearman-Brown SplitHalf Reliability analyses, correlation analyses between sounds, analyses of difference between the groups, and exploratory and confirmatory factor analyses, it can be said that the Thinking Creatively with Sounds and Words "Sounds and Images IIA Turkish" form is a valid and reliable measurement tool.

\section{References}

Batbay, D., Piji, D. (2006). The Relationship between Prospective Musical Teachers' Achievements in Music Lessons and Their Musical Creativity (Müzik Öğretmeni Adaylanının Müzik Dederslerindeki Başarıları ile Müzikal Yaratıclıklanı Arasındaki İlisski). MU Atatürk Education Faculty Journal of Educational Sciences. Issue 23, 51-68.

Büyüköztürk, Ş., (2009). Data Analysis Guide for Social Sciences (Sosyal Bilimler İçin Veri Analizi El Kitabı). Ankara: Pegem Academy Publications.

Büyüköztürk, Ş., Çokluk, Ö., Köklü, Ö. (2013). Statistics for Social Sciences. Ankara: Pegem Academy Publications.

Can, A. (2013). Quantitative Data Analysis in the Scientific Research Process with SPSS (SPSS ile Bilimsel Araştırma Sürecinde Nicel Veri Analizi). Ankara: Pegem Academy Publications.

Çokluk, Ö., Şekercioğlu, G., Büyüköztürk, Ş. (2012). Multivariate Statistics SPSS and Lisrel Applications for Social Sciences (Sosyal Bilimler İçin Çok Değişkenli İstatistik SPSS ve Lisrel Uygulamaları). Ankara: Pegem Academy.

Karasar, N. (2006). Scientific Research Method (Bilimsel Araştırma Yöntemi). Ankara: Nobel Publishing.

Khatena, J., Torrance, E.P. (1998). Thinking Creatively with Sound and Words Norms-Technical Manual. USA: Scholastic Testing Service Inc.

Öner, N. (2012). Examples from Psychological Tests Used in Turkey, An Application Source (Türkiye'de Kullanılan Psikolojik Testlerden Örnekler Bir Başvuru Kaynağı). İstanbul: Boğaziçi University Publishing.

Rouquette, M-L. (1992). Creativity (Yaratıc1l1k). (Gürbüz, I., Trans.). İstanbul: İletişim Publications. (Orginal work published 1989).

Sungur, N. (1992). Creative Thought (Yaratıcı Düşünce). İstanbul: Özgür Publishing-Distribution.

Şencan, H. (2005). Reliability and Validity in Social and Behavioral Measurements (Sosyal ve Davranışsal Ölçümlerde Güvenirlik ve Geçerlik). Ankara: Seçkin Publishing.

Torrance, P., Khatena, P., Cunnington, B. F. (1990). Thinking Creatively with Sound and Words Directions manual and Scoring Guide. USA: Scholastic Testing Service Inc.

Thinking Creatively with Sounds and Words (TCSW) $<$ http://ststesting.com/2005gifttcs w.html $>$ (Last access date: 17.11.2017).

Üstündağ, T. (2011). Journey to Creativity (Yaratıc1lı̆ga Yolculuk). Ankara: Pegem Academy Publications.

Yavuzer, H. S. (1989). Creativity (Yaratıcılık). İstanbul: Boğaziçi University Press.

Yılmaz, V., Çelik, H. E. (2009). Structural Equality Modeling with LISREL- I (LISREL ile Yapısal eşitlik Modellmesi- I). Ankara: Pegem Academy Publications. 